\title{
POLYCHLORINATED DIBENZODIOXINS AND DIBENZOFURANS EMISSIONS FROM TRANSPORTATION
}

Measurement of Persistent Organic Pollutants (POPS) was performed in order to complement the set of known emission factors. Methodology for gasoline engines emission factors determination that uses POPs concentrations measured in exhaust gasses, limited pollutants emission factors (carbon monoxide $\mathrm{CO}$, nitrogen oxides $\mathrm{NO}_{x}$ and hydrocarbons $\mathrm{HC}$ ) and other compounds (carbon dioxide $\mathrm{CO}_{2}$ ) was elaborated. Empirical value of exhaust gasses production announced by specialists of TUV SUD was used for diesel. Emission factors of four vehicle-fuel systems were determined particularly 11 congeners of Polychlorinated Dibenzodioxins (PCDDs), 34 congeners of Polychlorinated Dibenzofurans (PCDFs) and their toxic equivalents (TEQ) for each of the measured system. TEQ PCDD/F congener profile typical for POPS sources from transportation was compiled on the basis of measured data.

\section{Introduction}

Persistent Organic Pollutants (POPs) represent group of organic compounds with specific physico-chemical and environmental-chemical properties. The most important among them are resistance to diverse degradation processes, low solubility in water, lipophilic character. These properties results in high tendency for bioaccumulation, semi volatility enabling global atmospheric transport and significant adverse effects on human health or environment. Polychlorinated Dibenzodioxins (PCDDs) and Polychlorinated Dibenzofurans (PCDFs) belong among others to this group of compounds. They originate during communal, hospital or dangerous wastes incineration, also during coal, peat and wood combustion and can be also determined in vehicles emissions [1]. Their content in exhaust gasses is in very small concentrations and because of difficult and complicated analytical determination these compounds are measured in exhaust gasses only sporadically [2].

\section{Measurements methodology}

Emission factors (Ef) measurements of three vehicles using four different types of fuel were performed in two sampling campaigns in 2009 and 2010. Standard city cycle in accordance with ECE 83.04B consisting of 4 cycles ECE 15 in $195 \mathrm{sec}$. (Fig. 1) in three repetitions with previous 5 minutes engine heating up to running temperature (SDC) was chosen to simulate urban driving. Sufficient amount of exhaust gasses for PCDD/Fs and Polyaromatic Hydrocarbons (PAH) determination was sampled during these three cycles. Sampling was performed by using apparatus described in Fig. 2 connected directly to exhaust pipe. All measurements were performed in authorized station for vehicles homolo- gation TUV SUD on dynamometer SCHENCK 364/GS56 that simulates flywheel mass and running resistance as if vehicle moves on the road.

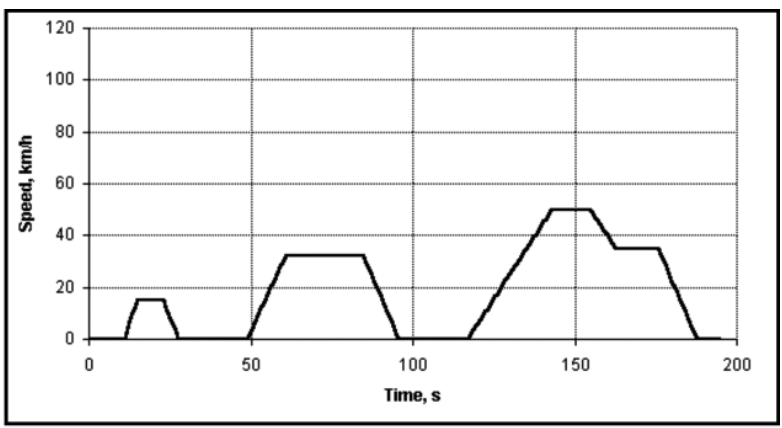

Fig. 1 Standard city cycle ECE 15

PCDD/Fs isotopic marked congeners were placed before the sampling to the sorption system to ensure control of PCDD/Fs sorption efficiency. Sampling and analyses were performed in accordance with CSN EN 1948-1-3 considering that measurements next to exhaust pipe was not possible to perform isokinetically. The same apparatus was used also for PAH sampling. Basic emission parameters such as $\mathrm{CO}_{2}, \mathrm{CO}, \mathrm{HC}, \mathrm{NO}_{2}$ were also measured at the same time.

Vehicle thus passed through the test in accordance with speed profile that is standard and described in ECE 83 regulation. Exhaust gasses were sampled in the whole volume using HORIBA CVS $7300 \mathrm{~T}$ device and were diluted to prevent condensation.

\footnotetext{
* Jiri Huzlik ${ }^{1}$, Roman Licbinsky ${ }^{1}$, Daniela Durcanska ${ }^{2}$

${ }^{1}$ Division of Transport Infrastructure and Environment, Transport Research Centre, Brno, Czech Republic, Email: jiri.huzlik@cdv.cz

${ }^{2}$ Faculty of Civil Engineering, University of Zilina, Slovakia
} 


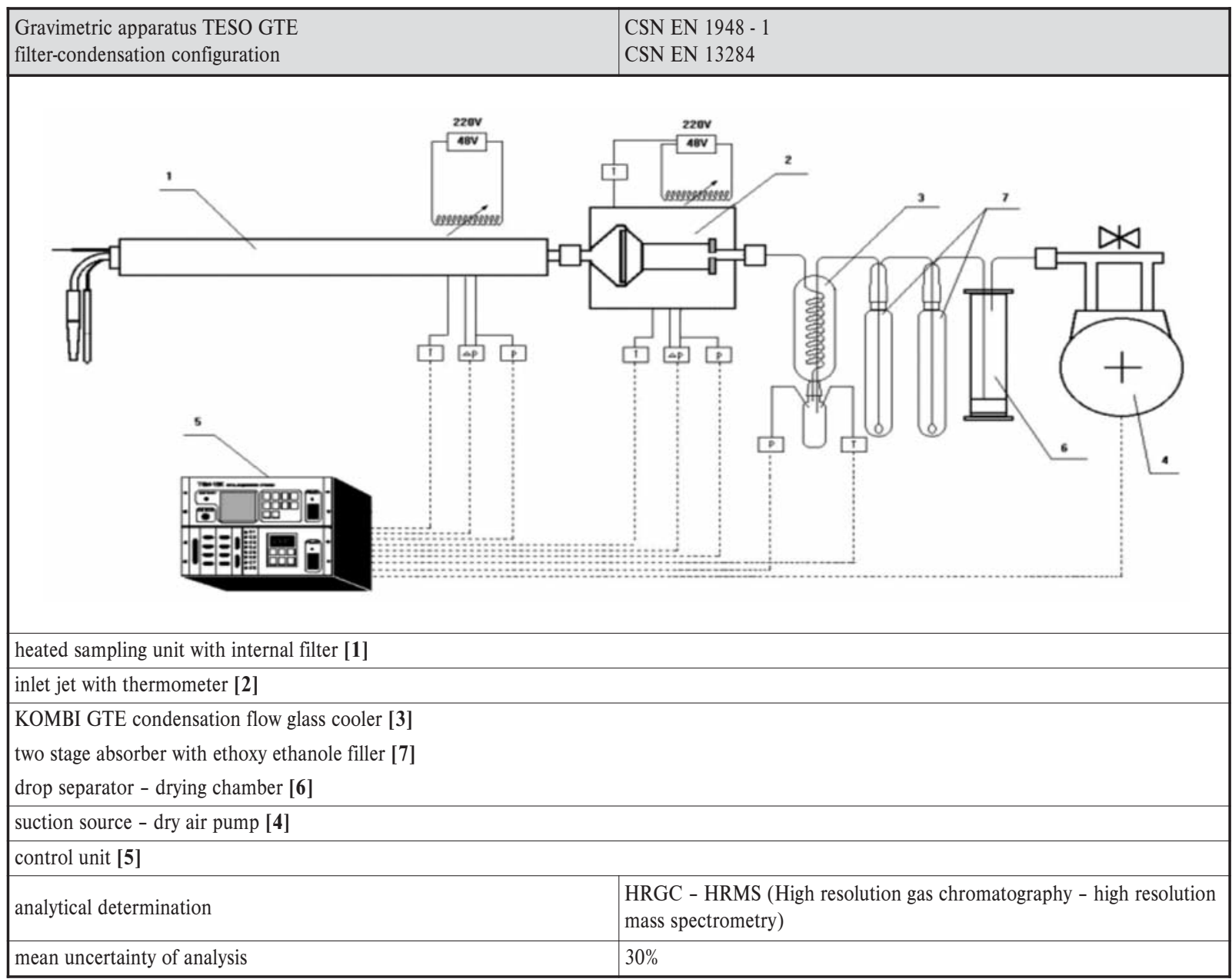

Fig. 2 Apparatus for PCDD/F and PAH sampling

Fuels used for measurements were tanked in common petrol stations. Their average chemical composition is characterised by parameters shown in Tab. 3. Symbols $n_{H}$ and $n_{C}$ mean the amount of hydrogen and carbon atoms in the mean molecule of fuel, $\rho_{p}$ means fuel density, BA is 95 octane gasoline and $\mathrm{MN}$ summer diesel fuel.

\section{Ef calculation methodology}

Methodology results from Ef values of $\mathrm{CO}, \mathrm{NO}_{\mathrm{x}}, \mathrm{CO}_{2}$ and $\mathrm{HC}$ measured in dry exhaust gasses on dynamometer by standard methods and from fuel consumption. Ef of pollutants are calculated from measured concentration and measured volumes of dry exhaust gasses used for chosen pollutants sampling under normal conditions $\left(101.325 \mathrm{kPa}, 0{ }^{\circ} \mathrm{C}\right)$.

Symbols marked with upper index on the right side are related to dry gasses that means to gasses without any water vapours. Amount of substances entering the combustion process are marked with capital $N$ with appropriate indexes, amount of substances of
Used symbols

Table 1

\begin{tabular}{|c|c|}
\hline$A_{i}$ & atomic weight of $i$-th element [g.mol-1] \\
\hline$a, b, c$ & $\begin{array}{l}\text { stoichiometric coefficients for elements in mean molecule of } \\
\text { fuel in sequence of } \mathrm{C}, \mathrm{H}, \mathrm{O}\end{array}$ \\
\hline$c_{i}^{s}$ & i-th component concentration in dry exhaust gasses $\left[\mathrm{g} \cdot \mathrm{m}^{-3}\right]$ \\
\hline $\operatorname{conc}_{i}^{s}$ & $\begin{array}{l}\text { i-th component content in dry exhaust gasses of the sample } \\
{\left[\text { g.sample }{ }^{-1}\right]}\end{array}$ \\
\hline$\beta$ & ratio of hydrogen atoms versus carbon atoms in fuel \\
\hline$\gamma$ & ratio of oxygen atoms versus carbon atoms in fuel \\
\hline$E f_{m}^{i}$ & i-th component emission factor $\left[\mathrm{g} \cdot \mathrm{kg}^{-1}\right]$ \\
\hline$E f_{1}^{i}$ & i-th component emission factor $\left[\mathrm{g} \cdot \mathrm{km}^{-1}\right]$ \\
\hline$F C$ & fuel consumption $\left[1 .(100 \mathrm{~km})^{-1}\right]$ \\
\hline$L$ & route passed by vehicle $[\mathrm{km}]$ \\
\hline$m_{i}$ & i-th component weight $[\mathrm{kg}]$ \\
\hline$M_{i}$ & i-th component molar weight $\left[\mathrm{g} \cdot \mathrm{mol}^{-1}\right]$ \\
\hline$\mu_{i}$ & $\begin{array}{l}\text { i-th component molar weight relative to one carbon atom in the } \\
\text { molecule }\left[\mathrm{g} \cdot \mathrm{mol}^{-1} \text { ] }\right.\end{array}$ \\
\hline
\end{tabular}




\begin{tabular}{|c|c|}
\hline$n_{i}$ & $\begin{array}{l}\text { amount of substance of i-th component content in exhaust } \\
\text { gasses [mol] }\end{array}$ \\
\hline$N_{i}$ & amount of substance of i-th component content in air [mol] \\
\hline$N_{p}$ & amount of substance of consumed fuel [mol] \\
\hline$N_{V}$ & $\begin{array}{l}\text { amount of substance of air entering the engine during fuel com- } \\
\text { bustion [mol] }\end{array}$ \\
\hline$\pi_{i}$ & i-th element percentage content in fuel [\%] \\
\hline$V_{a}$ & gas one mol volume under standard conditions $\left[1 . \mathrm{mol}^{-1}\right]$ \\
\hline$V^{s}$ & volume of dry gasses sample $\left[\mathrm{m}^{3}\right.$. sample $\left.{ }^{-1}\right]$ \\
\hline$V_{e x h}$ & $\begin{array}{l}\text { volume of dry exhaust gasses originated during fuel combustion } \\
{\left[\mathrm{m}^{3}\right]}\end{array}$ \\
\hline$\rho_{p}$ & fuel density $\left[\mathrm{kg} . \mathrm{l}^{-1}\right]$ \\
\hline
\end{tabular}

gasses in exhaust gasses are marked with $n$ with appropriate indexes. Index $p$ means fuel.

Physical constants used in calculations

Table 2

\begin{tabular}{|c|c|c|c|c|}
\hline Fuel & BA95 & LPG & $\mathrm{CNG}$ & $\mathrm{MN}$ \\
\hline Constant & \multicolumn{4}{|c|}{ Constant value } \\
\hline$M_{O_{2}}\left[\mathrm{~mol}^{\left.-\mathrm{g}^{-1}\right]}\right.$ & \multicolumn{4}{|c|}{31.9988} \\
\hline$M_{\mathrm{H}_{2} \mathrm{O}}\left[\mathrm{mol}^{-1} \mathrm{~g}^{-1}\right]$ & \multicolumn{4}{|c|}{18.0015} \\
\hline$M_{C O}\left[\mathrm{~mol}^{-1}\right]$ & \multicolumn{4}{|c|}{28.01055} \\
\hline$M_{N O}\left[\mathrm{~mol}_{\mathrm{g}}^{-1}\right]$ & \multicolumn{4}{|c|}{30.0061} \\
\hline$M_{\mathrm{NO}_{2}}\left[\mathrm{mol.g}^{-1}\right]$ & \multicolumn{4}{|c|}{46.0055} \\
\hline$M_{\mathrm{CO}_{2}}\left[\mathrm{~mol}^{-1}\right]$ & \multicolumn{4}{|c|}{44.00995} \\
\hline$V_{a}\left[\mathrm{~mol} . \mathrm{g}^{-1}\right]$ & \multicolumn{4}{|c|}{22.414} \\
\hline$M_{p}\left[\mathrm{~mol}_{\mathrm{g}} \mathrm{g}^{-1}\right]$ & 104.07 & 53.53 & 16.014 & 173.64 \\
\hline$A$ & 7.328 & 3.684 & 1 & 12.36 \\
\hline$\beta$ & 1.808 & 2.523 & 4 & 1.913 \\
\hline$\omega$ & 0.4389 & 0.6307 & 1 & 0.4739 \\
\hline$\pi_{O}[\%]$ & 2.73 & 0 & 0 & 0.92 \\
\hline$\rho_{p}\left[\mathrm{~kg} . \mathrm{l}^{-1}\right]$ & 0.748 & 0.538 & 0.000654 & 0.832 \\
\hline
\end{tabular}

It is necessary to know fuel composition when calculating Ef. The meanings of factors used for calculations are described in Table 1, physical constants in Table 2. Stoichiometric coefficients are introduced for simplification of further equations and their meaning is evident from equation (4)

$$
\omega=\frac{b-2 \cdot c}{4 \cdot a}=\frac{\beta}{4}-\frac{\gamma}{2} .
$$

If atomic ratio $\mathrm{H}: \mathrm{C}(=\beta)$ and oxygen percentage content $\pi_{O}$ are known, then

$$
\omega=\frac{\beta}{4}-\frac{\pi_{o} \cdot\left(A_{C}+\beta \cdot A_{H}\right)}{2 \cdot\left(100-\pi_{o}\right) \cdot A_{o}} .
$$

From the equation for fuel molecular weight relative to one carbon atom after substitution from (1) and (2), it holds

$$
\mu_{p}=\frac{M_{p}}{a}=A_{C}+\beta \cdot A_{H}+\gamma \cdot A_{o}=\frac{100 \cdot\left(A_{C}+\beta \cdot A_{H}\right)}{\left(100-\pi_{o}\right)}
$$

Emission factors of limited pollutants calculation results from equations of fuel combustion, mass balance and measured values. Fuel combustion is considered in some simplification (it is assumed that hydrocarbons contained in exhaust gasses are identical to those contained in fuel, origin of trace concentrations of $\mathrm{PAH}, \mathrm{N}_{2} \mathrm{O}, \mathrm{NH}_{3}$ and others are not considered):

$$
\begin{aligned}
& e / 2 \mathrm{~N}_{2}+\mathrm{C}_{a} \mathrm{H}_{b} \mathrm{O}_{c}+[a \cdot(1-z / 2)+b / 4-c / 2+ \\
& +e \cdot(1-w / 2)] \mathrm{O}_{2} \rightarrow a \cdot(1-\mathrm{z}) \mathrm{CO}_{2}+a \cdot z \mathrm{CO}+ \\
& +(b / 2) \mathrm{H}_{2} \mathrm{O}+e \cdot(1-w) \mathrm{NO}_{2}+\mathrm{e} \cdot \mathrm{w} \mathrm{NO} .
\end{aligned}
$$

Mass balance of real fuel combustion considering presumptions characterised above can be described by following equations for separate elements:

$$
\begin{aligned}
& \mathrm{C}: a \cdot\left(N_{p}-n_{p}\right)=n_{\mathrm{CO}_{2}}+n_{\mathrm{CO}} \\
& \mathrm{H}: \quad b \cdot\left(N_{p}-n_{p}\right)=2 \cdot n_{\mathrm{H}_{2} \mathrm{O}} \\
& \quad\left(N_{\mathrm{O}_{2}}-n_{\mathrm{O}_{2}}\right)+c \cdot\left(N_{p}-n_{p}\right)=n_{\mathrm{H}_{2} \mathrm{O}}+2 \cdot n_{\mathrm{CO}_{2}}+ \\
& \quad+n_{\mathrm{CO}}+2 \cdot n_{\mathrm{NO}_{2}}+n_{\mathrm{NO}} \\
& \mathrm{N}:\left(N_{\mathrm{N}_{2}}-n_{\mathrm{N}_{2}}\right)=n_{\mathrm{NO}_{2}}+n_{\mathrm{NO}} .
\end{aligned}
$$

Amount of substance of dry gasses enters combustion process

$$
N_{V}^{s}=N_{V}-N_{H_{2} O}=N_{N_{2}}+N_{O_{2}}+N_{C_{2}}
$$

and for amount of substance of dry gasses getting off the exhaust pipe holds

$$
\begin{aligned}
& n^{s}=n-n_{\mathrm{H}_{2} \mathrm{O}}=n_{\mathrm{N}_{2}}+n_{\mathrm{O}_{2}}+n_{\mathrm{CO}_{2}}+N_{\mathrm{CO}_{2}}+n_{\mathrm{CO}}+ \\
& +n_{p}+n_{\mathrm{NO}_{2}}+n_{\mathrm{NO}} .
\end{aligned}
$$

Symbol for i-th component concentration in entering air and in exhaust gasses formulated as molar fraction is described as

$$
Y_{i}^{s}=\frac{N_{i}}{N_{V}^{s}}, y_{i}^{s}=\frac{n_{i}}{n^{s}}, y_{i}=\frac{n_{i}}{n} .
$$

and equation solution for unknown parameters $N_{V}^{s}$ a $N_{p}$ brings formula necessary for further calculations

$$
\frac{N_{p}}{n^{s}}=\frac{Y_{O_{2}}^{s}-y_{O_{2}}^{s}+\left(1-Y_{O_{2}}^{s}\right) \cdot \frac{y_{C O}^{s}}{2}-\left(1-\frac{Y_{O_{2}}^{s}}{2}\right) \cdot y_{N O_{2}}^{s}-\frac{y_{N O}^{s}}{2}+\left(a \cdot(1+\omega)-(1+\omega) \cdot Y_{O_{2}}^{s}\right) \cdot y_{p}^{s}}{a \cdot\left(1+\omega \cdot\left(1-Y_{O_{2}}^{s}\right)\right)} .
$$


If pollutant concentration is expressed in mass units per volume unit, $E f$ of separate components of exhaust gasses relative to unit of consumed fuel can be described as

$$
E f_{m}^{i}=\frac{m_{i}}{m_{p}}=c_{i}^{s} \cdot \frac{V_{a}}{M_{p}} \cdot \frac{n^{s}}{N_{p}} .
$$

Ef expressed in mass units per passed route and concentration input data in mass unit per volume unit of exhaust gasses are calculated as

$$
E f_{l}^{i}=E f_{m}^{i} \cdot \frac{m_{p}}{l}=\frac{\operatorname{conc}_{i}^{s}}{V^{s}} \cdot \frac{V_{e x h}}{l} .
$$

Then results from equation (14) for rates for conversion from separate pollutants concentrations in exhaust gasses (POPs in this case) to $E f$ after substitution of the molar fraction from equation (11) and after neglecting $\mathrm{NO}_{2}$ concentration (NO predominantly originates during combustion):

\section{Results and discussion}

Emission factors of common pollutants that were also used for POPs Ef calculations are described in Table 3. Upper index $p$ means unburned hydrocarbons

Congener profiles for $j$-th measurement (17) or cumulative congener profiles (18) were compiled on the basis of measured data in accordance with following equations

$$
E f T E Q_{j}^{i}=E f_{j}^{i} \cdot T E Q_{j}^{i}
$$

$$
E f T E Q_{j}=\sum_{i} E f_{j}^{i} \cdot T E Q_{j}^{i}
$$

$$
\frac{V_{e x h}}{l}=\frac{V_{a}}{Y_{O_{2}}^{s}} \cdot\left(a \cdot \frac{F C \cdot \rho_{p}}{M_{p}} \cdot\left(1+\omega \cdot\left(1-Y_{O_{2}}^{s}\right)\right)+\frac{E f_{l}^{O_{4}}}{M_{O_{2}}}-\left(1-Y_{O_{2}}^{s}\right) \cdot \frac{E f_{l}^{C O}}{2 \cdot M_{C O}}-(1+\omega) \cdot\left(a-Y_{O_{2}}^{s}\right) \cdot \frac{E f_{l}^{p}}{M_{p}}+\frac{E f_{l}^{\mathrm{vO} O_{x}}}{2 \cdot M_{N O_{x}}}\right)
$$

The result from equation (14) is used for $E f$ calculation relative to passed route. After substitution of the result from equation (15) in dimensions described in Table 2 and after neglecting oxygen concentration in exhaust gasses, the formula for calculation of Ef of pollutants holds: where index i represents appropriate PCDD or PCDF congener. Cumulative Efs are counted above all PCDD and PCDF congeners. Following PCDD congeners and their toxic equivalents were considered:

$$
E f_{l}^{i}=\frac{\operatorname{conc}_{l}^{s} \cdot V_{a}}{1000 V^{s} \cdot Y_{O_{2}}^{s}} \cdot\left(a \cdot\left(1+\omega \cdot\left(1-Y_{O_{2}}^{s}\right)\right) \cdot \frac{10 \cdot F C \cdot \rho_{p}}{M_{p}}-\left(1-Y_{O_{2}}^{s}\right) \cdot \frac{E f_{l}^{C O}}{2 \cdot M_{C O}}-\frac{E f_{l}^{\mathrm{vO} O_{x}}}{2 \cdot M_{N O_{x}}}+(1+\omega) \cdot\left(a-Y_{O_{2}}^{s}\right) \cdot \frac{E f_{l}^{p}}{M_{p}}\right)
$$

Stoichiometric calculations without knowledge of oxygen concentration in exhaust gasses are not possible for diesel engines. Because of this fact it possible to use empirical value $1.2181 \mathrm{~m}^{3} \cdot \mathrm{km}^{-1}$ for recalculation of POPs concentrations in exhaust gasses in accordance with recommendation of authorized station for vehicles homologation TÜV SÜD.

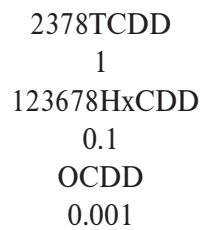

123478HxCDD

\begin{tabular}{|c|c|c|c|c|c|c|c|c|c|c|c|c|}
\hline Date & Vehicle type & Fuel & $\begin{array}{c}\rho_{p} \\
\mathrm{~kg} \cdot .^{-1}\end{array}$ & $n H / n C$ & $\% \mathrm{O}$ & $n C$ & Tachom. & $\begin{array}{l}E F_{l}^{C O_{2}} \\
\text { g.km }{ }^{-1}\end{array}$ & $\begin{array}{c}E F_{l}^{C O} \\
\text { g.km }\end{array}$ & $\begin{array}{c}E F_{l}^{p} \\
\text { g.km }\end{array}$ & $\begin{array}{l}E F_{l}^{N O_{\mathrm{x}}} \\
\mathrm{g} \cdot \mathrm{km}^{-1}\end{array}$ & $\begin{array}{l}F C .10^{2} \\
1 . \mathrm{km}^{-1}\end{array}$ \\
\hline 2.12 .09 & SKODA Felicia $1.3 / 50 \mathrm{kV}$ & A $95 \mathrm{t}$ & 0.748 & 1.85 & 2.7 & 6 & 65 & 242 & 0.716 & 0.136 & 0.178 & 10.27 \\
\hline 2.12 .09 & KODA Felicia 1.3/50 kW & LPG & 0.538 & 0.538 & 0 & 3.5 & 184981 & 193 & 10.49 & 0.91 & 0.223 & 13.05 \\
\hline 2.12 .09 & SKODA Fabia $1.4 / 44$ kW & $95 \mathrm{t}$ & 0.748 & 85 & 2.7 & 6 & 50389 & 243 & 0.826 & 0.105 & 0.497 & 10.28 \\
\hline 2.12 .09 & $\begin{array}{l}\text { SKODA Octavia } 1.9 \\
\text { TDI/77 kW }\end{array}$ & $\mathrm{MNt}$ & 0.832 & 1.91 & 0.92 & 12.36 & 156295 & 233 & 0.058 & 0.129 & 0.455 & 8.86 \\
\hline 22.9 .10 & SKODA Felicia $1.3 / 50 \mathrm{~kW}$ & BA 95t & 0.748 & 1.85 & 2.7 & 0 & 188083 & 267 & 0.682 & 0.088 & 0.133 & 11.3 \\
\hline 22.9 .10 & SKODA Felicia $1.3 / 50 \mathrm{~kW}$ & LPG & 0.538 & 0.538 & 0 & 3.5 & 188091 & 223 & 12.05 & 0.576 & 0.049 & 15.0 \\
\hline 22.9 .10 & SKODA Fabia 1.4/44 kW & BA 95t & 0.748 & 1.85 & 2.7 & 6 & 266232 & 215 & 0.568 & 0.042 & 0.443 & 9.1 \\
\hline 22.9 .10 & $\begin{array}{l}\text { SKODA Octavia } 1.9 \\
\text { TDI/77 kW }\end{array}$ & NMt & 0.832 & 1.91 & 0.92 & 12.36 & 179595 & 218 & 0.086 & 0.054 & 0.465 & 8.2 \\
\hline
\end{tabular}

0.1

$1234678 \mathrm{HpCDD}$

0.01

Results of limited pollutants emission factors measurements

Table 3

Legend: $t$ means tanked in petrol station (same in Table 4) 
and following PCDF congeners and their toxic equivalents were considered:

$\begin{array}{ccc}2378 \mathrm{TCDF} & 12378 \mathrm{PeCDF} & 23478 \mathrm{PeCDF} \\ 0.1 & 0.05 & 0.5 \\ 123478 \mathrm{HxCDF} & 123678 \mathrm{HxCDF} & \\ 0.1 & 0.1 & \\ & & \\ 234678 \mathrm{HxCDF} & 123789 \mathrm{HxCDF} & 1234678 \mathrm{HpCDF} \\ 0.1 & 0.1 & 0.01 \\ 1234789 \mathrm{HpCDF} & \text { OCDF } & \\ 0.01 & 0.001 & \end{array}$

TEQ PCDD a PCDF Ef congener profiles shown in Figs. 3 and 4 indicate higher values in 2010 but profiles for separate years of measurement can be considered as similar. TEQ 2378TCDD Ef was the highest in 2009 whereas $12378 \mathrm{PeCDD}$ Ef was the highest in 2010 among all PCDD congeners. 23478PeCDF Ef was the highest among all PCDF congeners in both measuring campaigns. TEQ OCDD and OCDF Ef were the lowest although TEQ 123789HxCDF Ef was once (Octavia 2010) the lowest.

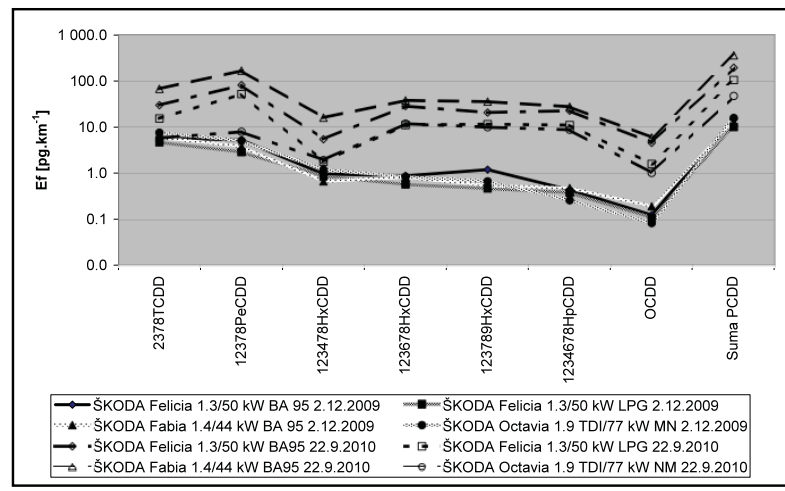

Fig. 3 TEQ-PCDD congener profiles

(logarithmic scale of $y$ axis)

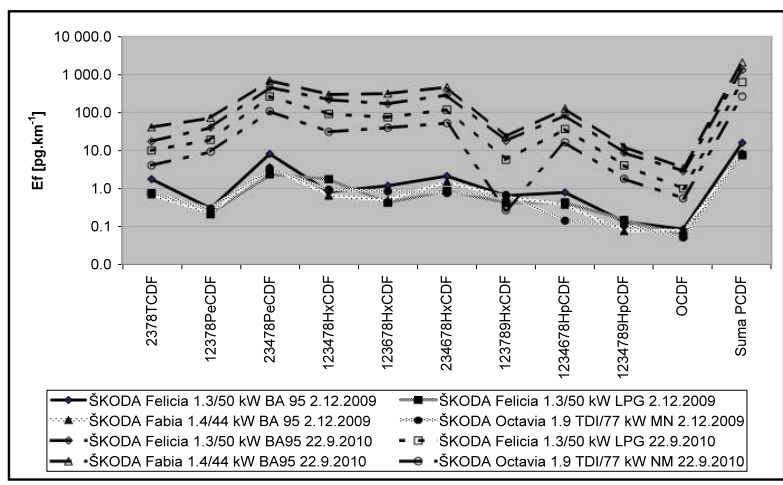

Fig. 4 TEQ-PCDF congener profiles

(logarithmic scale of $y$ axis)

Significant differences were found out among cumulative TEQ Ef in particular years. Predominant influence of Ef measured in

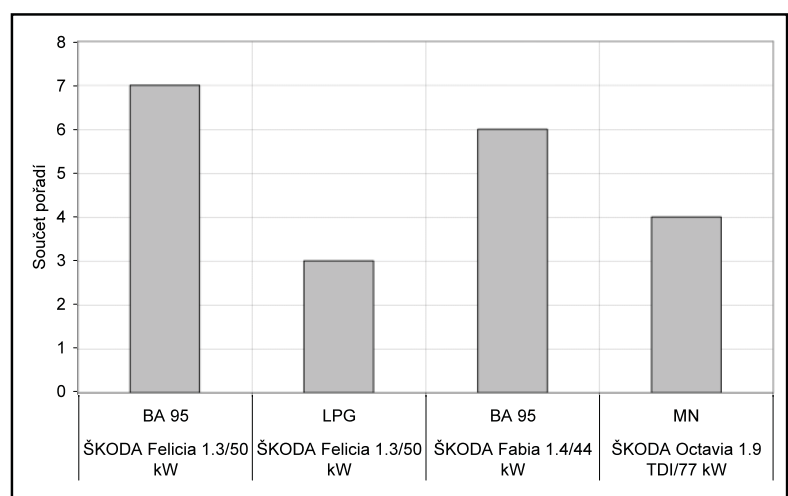

Fig. 5 Sum of rank of separate TEQ-PCDD/F emission factors of tested vehicles

2010 was demonstrated by comparison of arithmetic and geometric averages. Usage of sum of sequences of $E f$ measured in appropriate campaign and year according to their value is not dependent on absolute values of measured cumulative Ef (Fig. 5). In accordance with this criterion, PCDD/F Ef of Felicia with gasoline fuel had the highest toxic equivalent while PCDD/F Ef of the same vehicle using LPG fuel had the lowest toxic equivalent. Emission factors TEQ for conventional fuels (gasoline, diesel) decreased with decreasing age of vehicle. Usage of LPG in the same vehicle significantly decreased POPs emission in comparison with usage of conventional fuel. LPG had the lowest PCDD/F Ef among studied fuels.

Determined POPs Efs were compared with Efs measured by CDV for a wider selection of vehicles during 2005 - 2006 [3, 4]. Summary of measuring conditions in $2005-2010$ is outlined in Table 4. Most of fuels were certificated. Trend of dependency of cumulative PCDD/F Ef sums for separate vehicles and fuel on measuring date for separate measuring campaign (one day or two days) is shown in Fig. 6. Efs of cold starts (CS) are also shown in this graph. Cold start represents SDC without pre heating after vehicle parking outside whole night and its movement onto the dynamometer with engine off.

Efs had similar character of their time progress. This time progress was in four campaigns similar to time progress of PAH Efs. Data variance was larger within the sampling campaigns than among campaigns. Geometric averages of Efs measured in campaigns were in the range of units up to tens of pg. $\mathrm{km}^{-1}$ (in the frame in Fig. 6). However, PCDD/F Efs were in two campaigns in 2006 lower (tenths to units of pg. $\mathrm{km}^{-1}$ ) and in the last campaign in 2010, on the contrary, hundreds to thousands of pg. $\mathrm{km}^{-1}$.

Since differences in PAH Efs measurements in contrast to PCDD/F Efs were not relevant, entrance of different amounts of chlorine or its compounds to the measuring systems in these three campaigns than in others was considered. Probably these compounds were contained in the air entering combustion process in vehicles engines.

Cold starts Efs were higher than Efs measured under running conditions for all fuels which is probably determined by different 
Summary of cumulative emission factors measuring conditions in 2005-2010

Table 4

\begin{tabular}{|c|c|c|c|c|c|}
\hline Measurement No. & Identification & Vehicle type & Fuel & Comment & Passed km \\
\hline 6523 & F-BA 95 & SKODA Fabia 1.4/44 kW & Natural 95 & Certificated & 139500 \\
\hline 6522 & F-BA 95 & SKODA Fabia 1.4/44 kW & Natural 95 & Certificated & 139512 \\
\hline 6520 & F-BA 95-E5 & SKODA Felicia $1.3 / 50 \mathrm{~kW}$ & Natural 91 s $5 \%$ EtOH & Certificated & 139524 \\
\hline 6521 & F-BA 5-EE15 & SKODA Felicia $1.3 / 50 \mathrm{~kW}$ & Natural 91 s $15 \%$ ETBE & Certificated & 139536 \\
\hline 6518 & OS-MN & SKODA Octavia 1.9 SDI combi & MN, summer & Certificated & 82100 \\
\hline 6519 & OS-MN-M5 & SKODA Octavia 1.9 SDI combi & MN summer with $5 \%$ MERO & Certificated & 82112 \\
\hline 10542 & F-LPG & SKODA Felicia $1.3 / 50 \mathrm{~kW}$ & LPG & & 142900 \\
\hline 10544 & Fa-BA 95 & SKODA Fabia $1.4 / 44 \mathrm{~kW}$ & Natural 95 & Certificated & 179600 \\
\hline 10543 & Fa-BA 95-E5 & SKODA Fabia 1.4/44 kW & Natural 91 s $5 \%$ EtOH & Certificated & 179612 \\
\hline 10545 & Fa-BA 95-EE15 & SKODA Fabia 1.4/44 kW & Natural 91 s $15 \%$ ETBE & Certificated & 179624 \\
\hline 10546 & OS-MN-M31 & SKODA Octavia 1.9 SDI combi & MN summer with $31 \%$ MERO & Certificated & 93900 \\
\hline 14 & Fa-BA 95t-cs & SKODA Fabia 1.4/44 kW & BA95 tanked & Cold start & 183053 \\
\hline 15 & OS-MNt-cs & SKODA Octavia 1.9 SDI combi & MN tanked & Cold start & 96902 \\
\hline 16 & FF-E85 & Ford Focus Flexifuel & $85 \% \mathrm{EtOH}$ & & 2900 \\
\hline 17 & FF-E85-cs & Ford Focus Flexifuel & $85 \% \mathrm{EtOH}$ & Cold start & 2912 \\
\hline 2398 & FM-CNG-cs & Fiat Multipla (manufactured CNG) & $\mathrm{CNG}$ & Cold start & $\mathrm{n} / \mathrm{a}$ \\
\hline 2399 & FM-CNG & Fiat Multipla (manufactured CNG) & $\mathrm{CNG}$ & & $\mathrm{n} / \mathrm{a}$ \\
\hline 2400 & FF-E85-cs & Ford Focus Flexifuel & $85 \% \mathrm{EtOH}$ & Cold start & 19888 \\
\hline 2401 & FF-E85 & Ford Focus Flexifuel & $85 \% \mathrm{EtOH}$ & & 19900 \\
\hline 2402 & Fa-BA 95t-cs & SKODA Fabia 1.4/44 kW & BA95 tanked & Cold start & 185914 \\
\hline 2403 & OS-MNt-cs & SKODA Octavia 1.9 SDI combi & MN tanked & Cold start & 105588 \\
\hline 2404 & OS-MN-M5 & SKODA Octavia 1.9 SDI combi & MN summer with $5 \%$ MERO & Certificated & 105600 \\
\hline 2405 & OS-MN-M31 & SKODA Octavia 1.9 SDI combi & MN summer with $31 \%$ MERO & Certificated & 105612 \\
\hline 5774 & Fa-BA 95t-cs & SKODA Fabia 1.4/44 kW & BA95 tanked & Certificated & 192888 \\
\hline 5775 & Fa-BA 95 & SKODA Fabia 1.4/44 kW & Natural 95 & Certificated & 192900 \\
\hline 5776 & Fa-95-E5 & SKODA Fabia 1.4/44 kW & Natural 91 with $5 \% \mathrm{EtOH}$ & Certificated & 192912 \\
\hline 5777 & Fa-BA 95-EE15 & SKODA Fabia 1.4/44 kW & Natural 91 with $15 \%$ ETBE & Certificated & 192924 \\
\hline 5778 & FaP-CNG & $\begin{array}{l}\text { SKODA Fabia 1,4 Combi } \\
\text { (reconstruction to CNG) }\end{array}$ & $\mathrm{CNG}$ & & 108200 \\
\hline 5779 & OS-N-M5 & SKODA Octavia 1.9 SDI combi & MN summer with $5 \%$ MERO & Certificated & 114700 \\
\hline 5780 & OS-N-M31 & SKODA Octavia 1.9 SDI combi & MN summer with $31 \%$ MERO & Certificated & 114712 \\
\hline 61700 & F-BA 95t & SKODA Felicia $1.3 / 50 \mathrm{~kW}$ & BA95 tanked & & 185000 \\
\hline 61701 & F-LPG & SKODA Felicia $1.3 / 50 \mathrm{~kW}$ & LPG & & 185012 \\
\hline 61702 & Fa-BA 95t & SKODA Fabia 1.4/44 kW & BA95 tanked & & 250400 \\
\hline 61703 & OT-MNt & SKODA Octavia $1.9 \mathrm{TDI} / 77 \mathrm{~kW}$ & MN, summer, tanked & & 156300 \\
\hline 68843 & F-BA 95t & SKODA Felicia $1.3 / 50 \mathrm{~kW}$ & BA95 tanked & & 188083 \\
\hline 68844 & F-LPG & SKODA Felicia $1.3 / 50 \mathrm{~kW}$ & LPG & & 188091 \\
\hline 68842 & Fa-BA 95t & SKODA Fabia 1.4/44 kW & BA95 tanked & & 266232 \\
\hline 68845 & OT-MNt & SKODA Octavia 1.9 TDI/77 kW & MN, summer, tanked & & 179595 \\
\hline
\end{tabular}




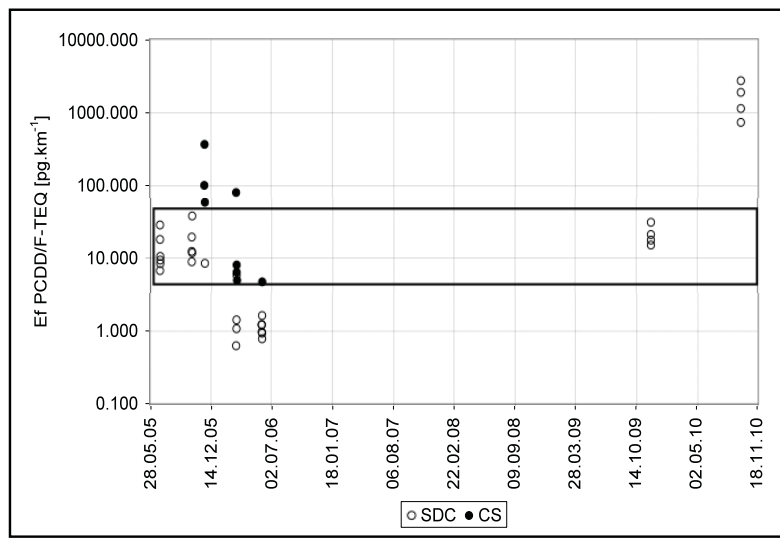

Fig. 6 Summary of cumulative PCDD/F emission factors measured by CDV (logarithmic scale)

conditions of combustion (lower temperatures, incomplete combustion)

Cumulative TEQ emission factors for all the measuring campaigns, all the tested vehicles and fuels shown in Fig. 7 in percentage were calculated in accordance with equation (19)

$$
E f T E Q^{i}=\frac{\sum_{j} E f_{j}^{i} \cdot T E Q_{j}^{i}}{\sum_{j} \sum_{i} E f_{j}^{i} \cdot T E Q_{j}^{i}} \cdot 100 .
$$

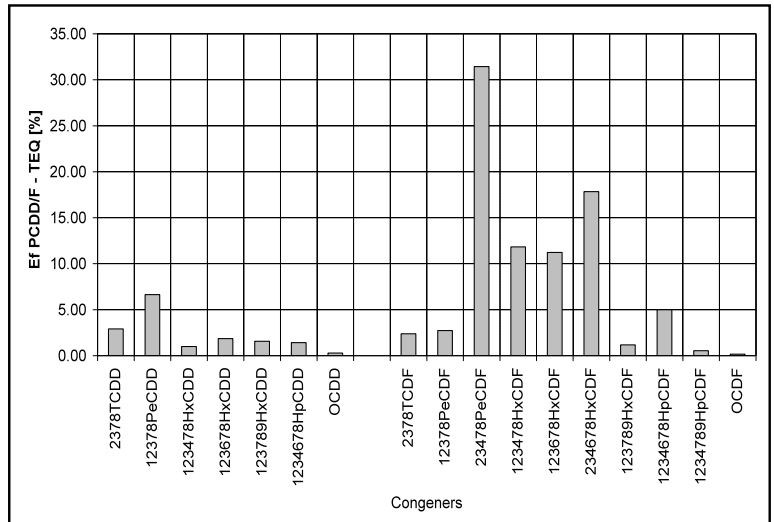

Fig. 7 Congener profile of TEQ PCDD/F emission factors mean values of all tested Vehicles

Congener profile calculated in accordance with equation (19) represents congener profile estimation of sources from individual passenger road transport.

\section{Acknowledgement}

This study was supported by the Czech Ministry of Transport within R\&D project "POPs emissions from transport" No. CG912-081-520.

\section{References:}

[1] HOlOUbeK I., KOCAN A., HOLOUBKOVA, I., KOHOUTEK J.: Persistent Organic Pollutants (in Czech), Edice Planeta, Vol. 9, No. 2, 2001, p. 13, ISSN: 1213-3396

[2] SEBOR G., KOZAK P., POSPISIL M., BLAZEK J.: Gasoline Properties and their Influence on Environment (in Czech), Chemicke listy 89, pp. 233-244, 1995

[3] JEDLICKA, J., ADAMEC, V., CHOLAVA, R., DUFEK, J., HUZLIK, J., OCELKA, J., GRABIC, R., CHMELOVA, M., VASUTOVA, L.: Nonlimited Pollutants Measurements and Emission Factors Calculations of Mixed Biofuels in Dependence on their Composition and Operating Mode (in Czech), Final report VaV 1F54G/104/520, CDV Brno, p. 32, 2007

[4] DUFEK, J., HUZLIK, J., DURCANSKA, D., SLANINKA, S.: Vehicles Emission Factors Corporate Database (in Slovak), Final report of a bilateral project Czech Republic - Slovak Republic, CDV Brno - Zilinska univerzita, 2006. 